\title{
Biosorption of acid dyes from aqueous solution using Curcuma angustifolia scales
}

\author{
Selvaraj Suresh* \\ Associate Professor, Department of Chemistry, A.C.T College of Engineering and Technology, Kancheepuram District - 603107. \\ India
}

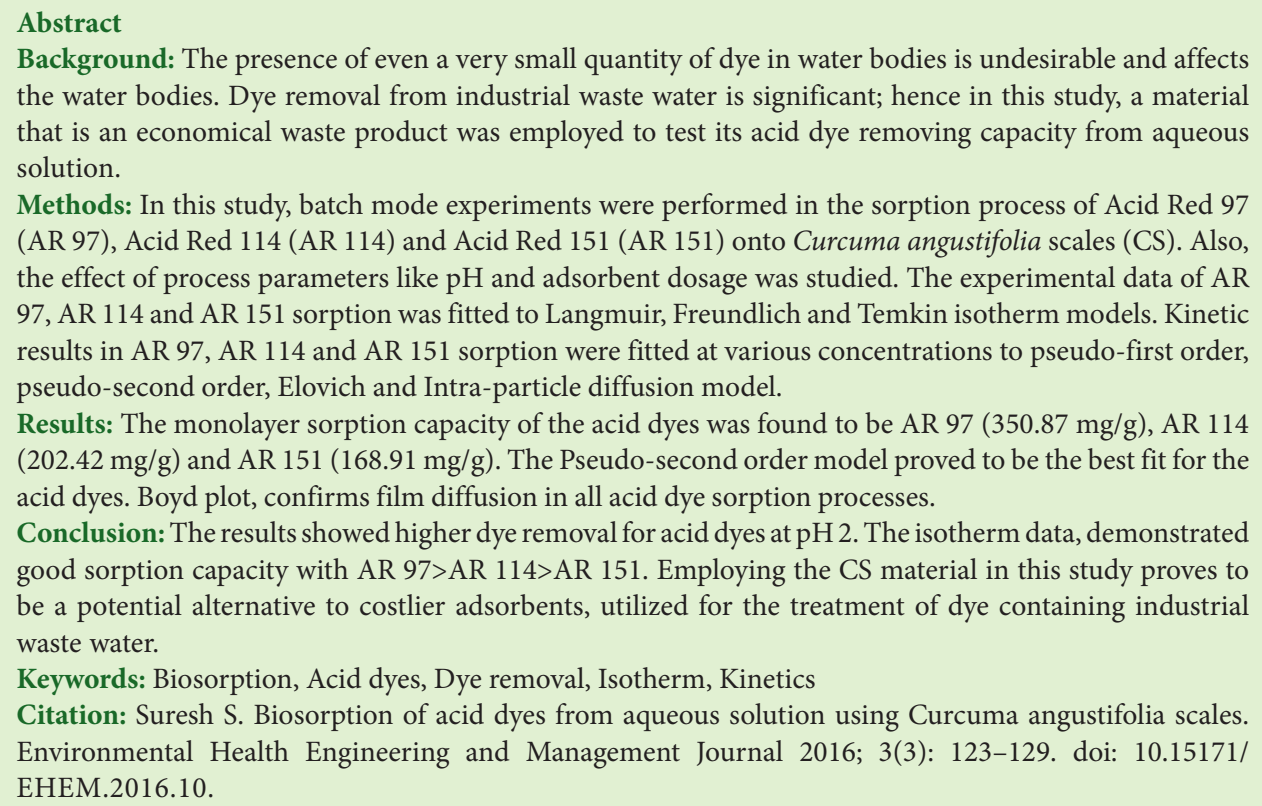

Article History:

Received: 17 May 2016

Accepted: 25 July 2016

ePublished: 27 August 2016

*Correspondence to:

Selvaraj Suresh

Email: drssureshchem@gmail.com

\section{Introduction}

The presence of dyes in textile industry effluents are usually non biodegradable, and leads to a serious threat to human beings and the environment. The highly coloured dyes in effluent, affect sunlight penetration, and retard the photosynthetic activity, leading to reduction in the growth of aquatic biota in water bodies (1). The disposal of dye into water resources, damage the aquatic life and causes carcinogenic and mutagenic effects (2). Hence, colour removal from dye containing effluents by different treatment techniques becomes very important.

Since dyes are difficult to decolorize, there is need to obtain a technology that works well and cost effective for the treatment of effluents. Conventional treatment processes found to be effective in reducing the concentration of dye includes, photo degradation (3), coagulation (4), electrochemical oxidation (5), ozonation and coagulation, chemical oxidation $(6,7)$. The most commonly used method that is known to be efficient for the treatment of a wide range of dye in wastewater, is adsorption (8). Adsorption using activated carbon is one of the commonly utilized methods for the removal of dye in wastewaters. The high cost of activated carbon and the loss involved in regeneration, prompted the search for effective and inexpensive biosorbents (9) for wastewater treatment.

In developing countries, the high cost of activated carbon helped the search for low cost biosorbents for the treatment of colored effluents. Researchers have focused on the use of biosorbents in the treatment of colored water with variation in the degrees of success (10). Some of the biosorbents used are, sugarcane bagasse (11), sawmill waste (12), jackfruit leaf powder (13), waste pea shells (14), jute stick powder (15), soybeans meal hull (16), mansonia wood sawdust (17), etc. Still, it is necessary to search for effective biosorbents for the removal of dyes from wastewater.

The biosorbent employed in this study is a cheap material available free of charge in India; hence, it was employed in the present method of dye removal. In this work, the paper discusses the use of an effective and inexpensive natural raw Curcuma angustifolia Scales as biosorbent, for the removal of acid dyes from aqueous solution. 
Methods

Materials

In this study, C. angustifolia (CS) tubers were collected from Nagercoil, Tamil Nadu. The scales were removed from the tubers and used as biosorbent. The acid dyes employed in this study were Acid Red 97 (AR 97), Acid Red 114 (AR 114) obtained from Sigma-Aldrich (Bangalore, India), and Acid Red 151 (AR 151) obtained from SHIDIMO, Interaux Pvt. Ltd. India. The characteristics of the anionic dyes are as follows: AR 97 (CI: 22890; molecular weight: $698.32 \mathrm{~g} \mathrm{~mol}^{-1}$; molecular formula: $\mathrm{C}_{32} \mathrm{H}_{20} \mathrm{~N}_{4} \mathrm{Na}_{2} \mathrm{O}_{8} \mathrm{~S}_{2}$ ); AR 114 (CI: 23635; molecular weight: $830.81 \mathrm{~g} \mathrm{~mol}^{-1}$; molecular formula: $\mathrm{C}_{37} \mathrm{H}_{28} \mathrm{~N}_{4} \mathrm{Na}_{2} \mathrm{O}_{10} \mathrm{~S}_{3}$ ). AR 151 (CI: 26900; molecular weight: $454.43 \mathrm{~g} \mathrm{~mol}^{-1}$; molecular formula: $\mathrm{C}_{22} \mathrm{H}_{15} \mathrm{~N}_{4} \mathrm{NaO}_{4} \mathrm{~S}$ ). The dyes are utilized as coloring agent for fabrics in textile industries. The $\mathrm{pH}$ was adjusted using $\mathrm{HCl}$ solution and $\mathrm{NaOH}$ pellets, obtained from Merck, India. The molecular structure of AR 97, AR 114 and AR 151 is illustrated in Figure 1.

\section{Preparation of biosorbent}

The raw material CS scales were collected and washed with distilled water repeatedly, till the wash water is free from any color, to ensure the removal of dirt, dust and surface impurities. The material was kept in a hot air oven at $60^{\circ} \mathrm{C}$ for 24 hours. The dried biomass was grinded, using a domestic mixer. The grinded material was sieved to uniform particle size, in the range of 80-100 mesh (BSS). The biosorbent thus obtained, is labeled as CS (18).

\section{Batch sorption experiments}

Sorption studies, using fixed biosorbent mass at varying dye concentrations, were studied for the removal of acid

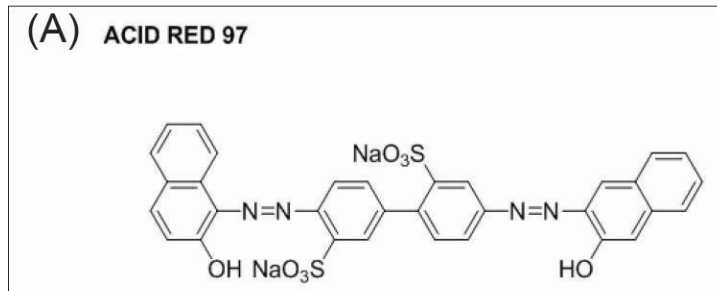

(B) ACID RED 114

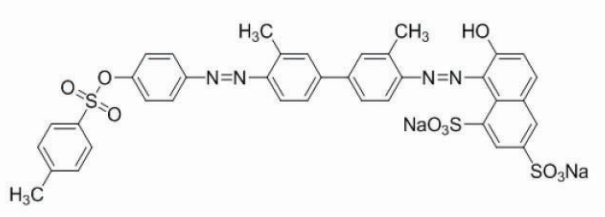

(C)

ACID RED 151

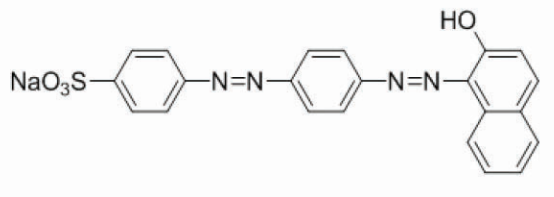

Figure 1. Molecular structure of acid dyes (A) AR 97 (B) Acid Red 114 (C) Acid Red 151. dyes at $\mathrm{pH}$ 2. To investigate the efficiency of dye removal and to study the isotherm constants, experiments were carried out with $50 \mathrm{~mL}$ of different dye concentration with $50 \mathrm{mg}$ of the biosorbent in a series of conical flasks. This mixture was kept on a mechanical shaker for a period of 4 hours at constant speed. The dye concentration at equilibrium was measured spectrophotometrically at the wavelength of maximum absorbance AR 97 (498 nm), AR $114(522 \mathrm{~nm})$ and AR $151(549 \mathrm{~nm})$. The percentage dye removal by the biosorbent was calculated using the formula:

\% Dye Removal $=\frac{C_{i}-C_{f}}{C_{i}} \times 100$

The amount of dye sorbed at equilibrium $\mathrm{q}_{\mathrm{e}}(\mathrm{mg} / \mathrm{g})$ was calculated by:

$q_{e}=C_{i}-C_{f} \times \frac{V}{M}$

Where $C_{i}$ and $C_{f}$ are the initial and final liquid phase concentrations $(\mathrm{mg} / \mathrm{L})$. The volume of acid dye solution $(\mathrm{V})$ in $\mathrm{mg} / \mathrm{L}$ and the biosorbent mass $(\mathrm{g})$ is given by $\mathrm{M}$.

\section{Results}

Studies on $\mathrm{pH}$ and biosorbent dosage

In the present study of $\mathrm{pH}$, the percentage dye removal for $50 \mathrm{~mL}$ of $100 \mathrm{mg} / \mathrm{L}$ of dyes was mixed with $0.1 \mathrm{~g}$ of biosorbent, and was observed in the $\mathrm{pH}$ range of 2 to 12 for all three acid dyes (Figure 2). To investigate the effect of sorbent dosage onto AR 97, AR 114 and AR 151, a dye concentration of $100 \mathrm{mg} / \mathrm{L}$ in a series of standard $50 \mathrm{~mL}$ dye volume was taken at $\mathrm{pH} 2$, with all other experimental conditions constant. The graphical results are shown in Figure 3.

Isotherm studies

The isotherm data for the biosorption of AR 97, AR 114 and AR 151 onto the biosorbent was analyzed by means of Langmuir, Freundlich and Temkin (19) model. The obtained isotherm parameters, using the linear form of the isotherm equations are given in Table 1 . Moreover, the $R_{L}$ value observed $\left(0<R_{\mathrm{L}}<1\right)$, linear $\left(R_{\mathrm{L}}=1\right)$, unfavorable $\left(R_{\mathrm{L}}\right.$ $>1$ ) or irreversible $R_{\mathrm{L}}=0$, indicates that in CS, a favorable

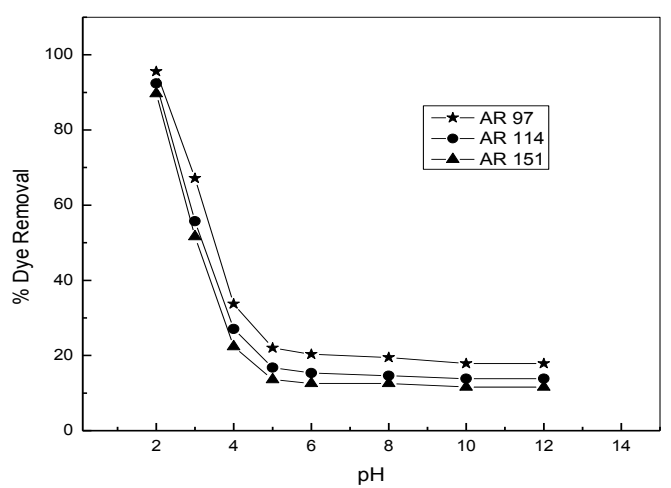

Figure 2. Effect of $\mathrm{pH}$ in sorption of acid dyes onto Curcuma angustifolia Scales $\left(C_{0}=100 \mathrm{mg} / \mathrm{L} ; \mathrm{m}=100 \mathrm{mg} ; \mathrm{V}=0.05 \mathrm{~L}\right)$. 


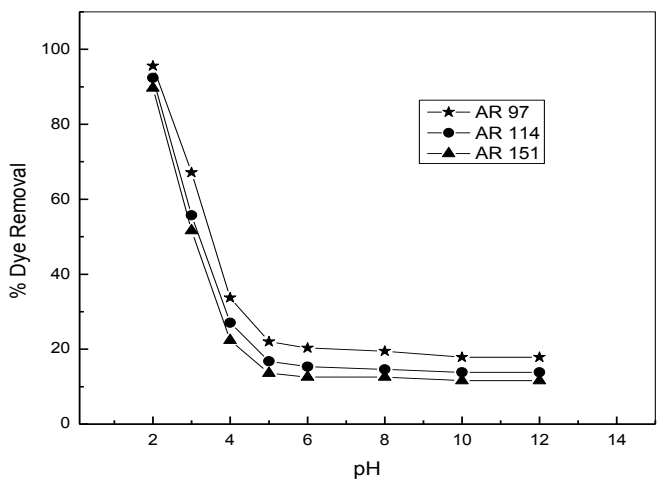

Figure 3. Effect of biosorbent dosage in the sorption of acid dyes onto Curcuma angustifolia scales $(\mathrm{C} 0=100 \mathrm{mg} / \mathrm{L} ; \mathrm{V}=0.05 \mathrm{~L})$.

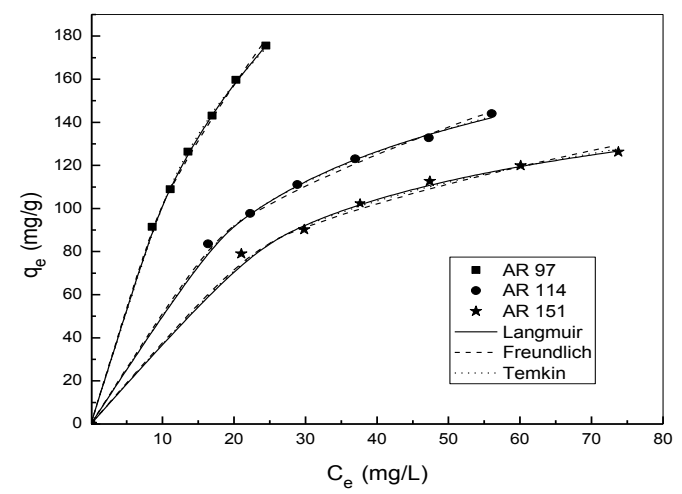

Figure 4. The fit of experimental data for the sorption of acid dyes onto Curcuma angustifolia scales ( $\mathrm{t}=4$ hours; $\mathrm{m}=50 \mathrm{mg} / 0.05 \mathrm{~L}$ )

Table 1. Langmuir, Freundlich and Temkin constants for the biosorption of acid dyes onto Curcuma angustifolia

\begin{tabular}{lccc}
\hline Langmuir constants & AR 97 & AR 114 & AR 151 \\
\hline $\mathrm{Q}_{\mathrm{m}}(\mathrm{mg} / \mathrm{g})$ & 350.87 & 202.42 & 168.91 \\
$\mathrm{~K}_{\mathrm{L}}(\mathrm{L} / \mathrm{mg})$ & 0.0409 & 0.0421 & 0.0407 \\
$\mathrm{R}^{2}$ & 0.9936 & 0.9985 & 0.9911 \\
$\mathrm{R}_{\mathrm{L}}$ & $0.1965-0.1089$ & $0.1919-0.1061$ & $0.1972-0.1094$ \\
Freundlich constants & & & \\
$\mathrm{K}_{\mathrm{F}}(\mathrm{mg} / \mathrm{g})$ & 24.27 & 25.26 & 24.71 \\
$\mathrm{n}$ & 1.6023 & 2.3041 & 2.5953 \\
$\mathrm{R}^{2}$ & 0.9955 & 0.9923 & 9809 \\
Temkin constants & & & \\
$\mathrm{KT}(\mathrm{L} / \mathrm{mg})$ & 0.353 & 0.3423 & 0.3573 \\
$\mathrm{~B} 1$ & 80.84 & 48.34 & 39.03 \\
$\mathrm{R} 2$ & 0.9976 & 0.9975 & 0.9903 \\
\hline
\end{tabular}

sorption process occurs for the acid dyes. The Freundlich constants were determined from the linear form of the model, and the value of $\mathrm{K}_{\mathrm{F}}, \mathrm{n}$ and the correlation coefficients are given in Table 1 .

The Temkin isotherm constants for biosorption of AR 97, AR 114 and AR 151 onto CS calculated from the plot of qe vs. $\operatorname{lnCe}$ are given in Table 1 . The comparative fit of experimental data for sorption of AR 97, AR 114 and AR 151 onto CS is shown in Figure 4.

Studies on sorption kinetics and mechanism In order to analyze the biosorption kinetics, pseudo-first order, pseudo-second order, Elovich and intraparticle diffusion equations (19) were utilized. A plot of $\log \left(\mathrm{q}_{\mathrm{e}}-\mathrm{q}_{\mathrm{t}}\right)$ vs. time for CS to enable the calculation of the rate constant $\mathrm{K}_{1}$ and the results are tabulated in Table 2. The kinetic data was tested for designing and modeling the sorption process, employing the pseudo-second order model and the best fit was investigated (Figure 5). Table 2 presents the various kinetic constants and $\mathrm{q}_{\mathrm{e}(\mathrm{calc})}$ in the sorption of $\mathrm{AR}$ 97, AR 114 and AR 151 onto the biosorbent. The Elovich constants $\alpha$ and $\beta$ calculated for the acid dye sorption is shown in Table 3. The intraparticle diffusion rate constant $\left(\mathrm{K}_{\mathrm{id}}\right)$ and the intercept $(\mathrm{C})$ was obtained for AR 97, AR 114 and AR 151 from the slope and intercept of the plot of $q_{t}$ vs. $t^{1 / 2}$, the results are presented in Table 3. The Boyd model is essential in predicting the rate limiting step, in
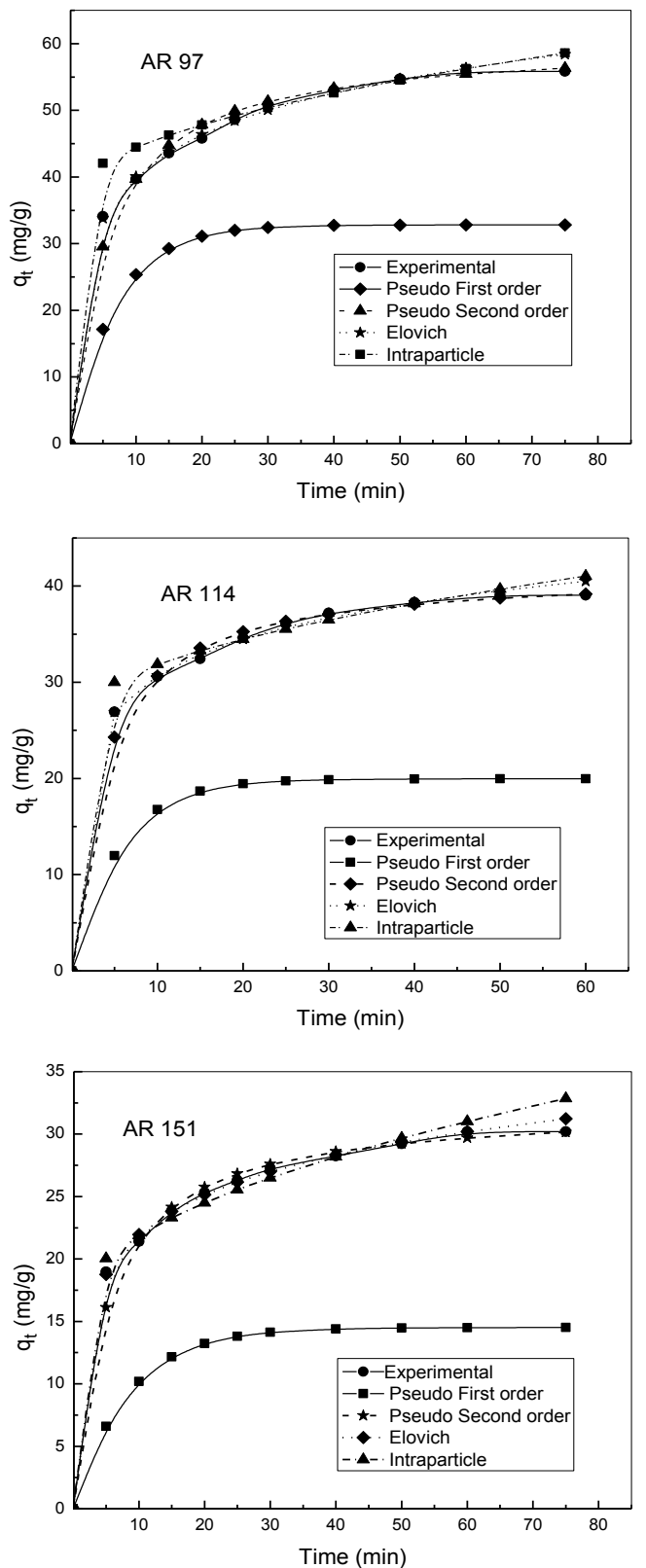

Figure 5. Comparison of various kinetic models with experimental values for the sorption of acid dyes onto Curcuma angustifolia scales ( $\mathrm{C} 0=140 \mathrm{ppm} ; \mathrm{m}=1 \mathrm{~g} / 0.5 \mathrm{~L})$ 
Table 2. Kinetic values for the biosorption of acid dyes on to CS.

\begin{tabular}{|c|c|c|c|c|c|c|c|c|c|}
\hline \multirow{2}{*}{ Adsorbent } & \multirow{2}{*}{$\begin{array}{l}\text { Concentration } \\
\mathrm{mg} / \mathrm{L}\end{array}$} & \multirow{2}{*}{$\begin{array}{l}q_{\text {e(exp) }} \\
(\mathrm{mg} / \mathrm{g})\end{array}$} & \multicolumn{3}{|c|}{ Pseudo first order } & \multicolumn{4}{|c|}{ Pseudo second order } \\
\hline & & & $\mathrm{q}_{\mathrm{e} \text { ( Calc) }}(\mathrm{mg} / \mathrm{g})$ & $K_{1}\left(\min ^{-1}\right)$ & $\mathbf{R}^{2}$ & $\mathrm{q}_{\mathrm{e}(\text { Calc })}\left(\mathrm{mg} \mathrm{g}^{-1}\right)$ & $\mathrm{K}_{2}\left(\mathrm{~g} \mathrm{mg}^{-1} \mathrm{~min}^{-1}\right)$ & $\mathrm{h}\left(\mathrm{mg} \mathrm{g}^{-1} \mathrm{~min}^{-1}\right)$ & $\mathbf{R}^{2}$ \\
\hline \multirow{4}{*}{ AR 97} & 100 & 48.77 & 32.68 & $6.43 \times 10^{-2}$ & 0.9860 & 52.91 & $3.32 \times 10^{-3}$ & 9.26 & 0.9987 \\
\hline & 140 & 55.83 & 32.82 & $6.31 \times 10^{-2}$ & 0.9870 & 60.24 & $3.19 \times 10^{-3}$ & 11.58 & 0.9989 \\
\hline & 180 & 58.53 & 34.29 & $6.26 \times 10^{-2}$ & 0.9818 & 62.89 & $3.16 \times 10^{-3}$ & 12.50 & 0.9989 \\
\hline & 220 & 64.31 & 35.75 & $6.11 \times 10^{-2}$ & 0.9841 & 68.95 & $2.95 \times 10^{-3}$ & 14.02 & 0.9988 \\
\hline \multirow{4}{*}{ AR 114} & 100 & 31.26 & 19.45 & $8.79 \times 10^{-2}$ & 0.9857 & 33.55 & $7.47 \times 10^{-3}$ & 8.41 & 0.9992 \\
\hline & 140 & 39.24 & 19.95 & $7.97 \times 10^{-2}$ & 0.9897 & 41.49 & $6.85 \times 10^{-3}$ & 11.01 & 0.9993 \\
\hline & 180 & 40.33 & 22.51 & $7.91 \times 10^{-2}$ & 0.9661 & 43.10 & $5.93 \times 10^{-3}$ & 11.81 & 0.9988 \\
\hline & 220 & 44.37 & 23.29 & $7.28 \times 10^{-2}$ & 0.9574 & 47.61 & $5.14 \times 10^{-3}$ & 11.65 & 0.9982 \\
\hline \multirow{4}{*}{ AR 151} & 100 & 20.10 & 13.57 & $5.87 \times 10^{-2}$ & 0.9804 & 22.17 & $6.26 \times 10^{-3}$ & 3.05 & 0.9976 \\
\hline & 140 & 30.19 & 14.51 & $5.85 \times 10^{-2}$ & 0.9853 & 32.15 & $6.20 \times 10^{-3}$ & 6.47 & 0.9989 \\
\hline & 180 & 34.11 & 18.41 & $5.83 \times 10^{-2}$ & 0.9827 & 36.13 & $5.17 \times 10^{-3}$ & 6.93 & 0.9986 \\
\hline & 220 & 38.66 & 20.12 & $5.27 \times 10^{-2}$ & 0.9894 & 41.32 & $4.80 \times 10^{-3}$ & 8.30 & 0.9988 \\
\hline
\end{tabular}

Table 3. Intraparticle and Elovich values for the biosorption of acid dyes on to Curcuma angustifolia

\begin{tabular}{|c|c|c|c|c|c|c|c|}
\hline \multirow{2}{*}{ Adsorbent } & \multirow{2}{*}{$\begin{array}{c}\text { Concentration } \\
\mathrm{mg} / \mathrm{L}\end{array}$} & \multicolumn{3}{|c|}{ Intraparticle diffusion } & \multicolumn{3}{|c|}{ Elovich } \\
\hline & & $\mathrm{K}_{\mathrm{ip}}\left(\mathrm{mg} / \mathrm{g} \mathrm{min}^{1 / 2}\right)$ & $\mathrm{C}(\mathrm{mg} / \mathrm{g})$ & $\mathbf{R}^{2}$ & $\alpha$ (mg/g min) & $\beta$ (g/mg) & $\mathbf{R}^{2}$ \\
\hline \multirow{4}{*}{ AR 97} & 100 & 2.33 & 31.36 & 0.9885 & 40.94 & 0.1132 & 0.9907 \\
\hline & 140 & 2.52 & 36.31 & 0.9635 & 74.94 & 0.1101 & 0.9955 \\
\hline & 180 & 2.58 & 39.34 & 0.9741 & 91.62 & 0.1099 & 0.9905 \\
\hline & 220 & 2.70 & 43.73 & 0.9815 & 127.79 & 0.1090 & 0.9902 \\
\hline \multirow{4}{*}{ AR 114} & 100 & 1.15 & 23.25 & 0.9115 & 59.35 & 0.2004 & 0.9833 \\
\hline & 140 & 1.38 & 28.33 & 0.9768 & 126.25 & 0.1823 & 0.9915 \\
\hline & 180 & 1.73 & 29.42 & 0.9855 & 147.40 & 0.1723 & 0.9906 \\
\hline & 220 & 2.12 & 29.61 & 0.9765 & 162.33 & 0.1624 & 0.9825 \\
\hline \multirow{4}{*}{ AR 151} & 100 & 1.19 & 10.99 & 0.9873 & 11.83 & 0.2598 & 0.9890 \\
\hline & 140 & 1.37 & 19.58 & 0.9922 & 48.57 & 0.2171 & 0.9950 \\
\hline & 180 & 1.46 & 22.87 & 0.9766 & 54.06 & 0.1835 & 0.9818 \\
\hline & 220 & 1.59 & 26.36 & 0.9837 & 66.39 & 0.1675 & 0.9847 \\
\hline
\end{tabular}

the sorption of AR 97, AR 114 and AR 151 onto CS. Bt vs. time plot (Figure 6) can be used to test the linearity of the experimental values. The Di values were obtained for all acid dyes, using the calculated $B$ values and the calculated Di values for AR 97, AR 114 and AR 151 as shown in Table 5.

\section{Discussion}

Effect of $\mathrm{pH}$

From Figure 2, it is obvious that the solution pH affects the amount of dye, adsorbed with a high percentage dye removal for $\mathrm{AR}$ 97, $\mathrm{AR} 114$ and $\mathrm{AR} 151$ at $\mathrm{pH}$ 2. The dye removal increases drastically below $\mathrm{pH} 4$ to $\mathrm{pH} 2$ and higher dye removal of acid dyes was observed at $\mathrm{pH}$ 2 for all acid dyes, as a result, further adsorption work was carried out in the optimum $\mathrm{pH} 2$. At lower $\mathrm{pH}$, the surface of the biosorbent will react as positively charged, and hence, effectively attracts the negatively charged anionic dye, leading to an increased sorption of acid dyes. At higher $\mathrm{pH}$, the surface of the biosorbent becomes negatively charged, which reduces the interaction of the anionic dye. Literature also reveals a similar phenomenon for the removal of acid dyes using soybeans meal hull (16).

Effect of biosorbent dosage

It was observed that the percentage dye removal increases for the dyes AR 97, AR 114 and AR 151 with an increase in the amount of biosorbent, owing to the availability of more sorption sites with increased biosorbent dosage. As observed from Figure 3, the dye removal increases from 20 to $120 \mathrm{mg}$ for all acid dyes with more dye uptake in between 40 to $80 \mathrm{mg}$ for all acid dyes, and reaches a limit for dye sorption of $120 \mathrm{mg}$, reaching saturation of the active sites in the biosorbent (16).

Biosorption isotherms

The study on sorption isotherm of CS onto AR 97, AR 114 and AR 151 is necessary from theoretical and practical point of view. The high $\mathrm{R}^{2}$ value implies the applicability of the Langmuir isotherm in all three acid dye sorption processes. The experimental data for all dyes provide the best correlation to Langmuir isotherm, indicating the homogenous nature of the biosorbent surface and hence, showing the monolayer coverage of the all dyes onto the 
Table 4. Biosorbents reported for the removal of acid dye from aqueous solution.

\begin{tabular}{lccc}
\hline Biosorbent & Dyes & $\mathbf{q}_{\mathbf{m}}(\mathbf{m g} / \mathbf{g})$ & Reference \\
\hline Bagasse pith & Acid Red 114 & 101 & $(26)$ \\
Orange peel & Acid violet 17 & 19.88 & $(27)$ \\
Coir pith & Acid brilliant Blue & 16.67 & $(28)$ \\
Lady's Finger & Acid Blue 113 & 169.9 & $(29)$ \\
Soy meal hull & Acid Blue 92 & 114.94 & $(16)$ \\
& Acid Red 14 & 109.84 & $(16)$ \\
Hazelnut shell & Acid Blue 25 & 60.2 & $(30)$ \\
Wood sawdust & Acid Blue 25 & 5.92 & $(31)$ \\
\multirow{2}{*}{ Curcuma angustifolia } & Acid Red 97 & 350.87 & This work \\
Scales & Acid Red 114 & 202.42 & This work \\
& Acid Red 151 & 168.91 & This work \\
\hline
\end{tabular}

Table. 5. Diffusion coefficient $\left(D_{i}\right)$ for biosorption of acid dyes onto Curcuma angustifolia

\begin{tabular}{lcl}
\hline Adsorbent & Concentration $(\mathrm{mg} / \mathrm{L})$ & $\mathbf{D}_{\mathrm{i}}\left(\mathrm{cm}^{2} / \mathrm{s}\right)$ \\
\hline & 100 & $8.52 \times 10^{-11}$ \\
AR 97 & 140 & $7.52 \times 10^{-11}$ \\
& 180 & $7.34 \times 10^{-11}$ \\
& 220 & $7.41 \times 10^{-11}$ \\
& 100 & $1.03 \times 10^{-10}$ \\
AR 114 & 140 & $9.35 \times 10^{-11}$ \\
& 180 & $9.34 \times 10^{-11}$ \\
& 220 & $8.54 \times 10^{-11}$ \\
AR 151 & 100 & $6.67 \times 10^{-11}$ \\
& 140 & $6.18 \times 10^{-11}$ \\
& 180 & $6.83 \times 10^{-11}$ \\
& 220 & $6.84 \times 10^{-11}$ \\
\hline
\end{tabular}

biosorbent surface (20). The $\mathrm{R}_{\mathrm{L}}$ calculated from the results using Eq. 3 were found to be in the range of 0.1965 to 0.1089 for AR 97, 0.1919 to 0.1061 for AR 114 and 0.1972 to 0.1094 for AR 151 .

$R_{\mathrm{L}}=1 /\left(1+K_{\mathrm{L}} C_{0}\right)$

Since the biosorbent has good adsorption for AR 97, AR 114 and AR 151; the material can be a good alternative to commercial activated carbon in the removal of dye from aqueous solution.

From Table 1, the maximum monolayer sorption capacity $\left(\mathrm{Q}_{\mathrm{m}}\right)$ for the acid dyes was found to be 350.87 for AR 97, 202.42 for AR 114 and $168.91 \mathrm{mg} / \mathrm{g}$ for AR 151. The higher sorption of the dyes AR 97, AR 114 and AR 151 on the biosorbent could be due to the surface charge present on the dye surface, interacting effectively with the biosorbent surface. The applicability of the Langmuir model to all three dyes is proved by the high correlation coefficients $R^{2}$ $>0.99$, suggesting that the Langmuir isotherm provides a good model of the sorption system (21).

In Freundlich isotherm, the biosorption capacity is related to the constant $\mathrm{K}_{\mathrm{F}}$ and the magnitude of the component ' $\mathrm{n}$ ' indicates the favorability of sorption process. According to Treybal (22), it has been demonstrated that $n>1$, represents favorable sorption. The $n$ values of the acid dyes indicate favorable sorption onto the biosorbent. The $n$ value was found to be 1.60 for AR 97, 2.30 for AR 114
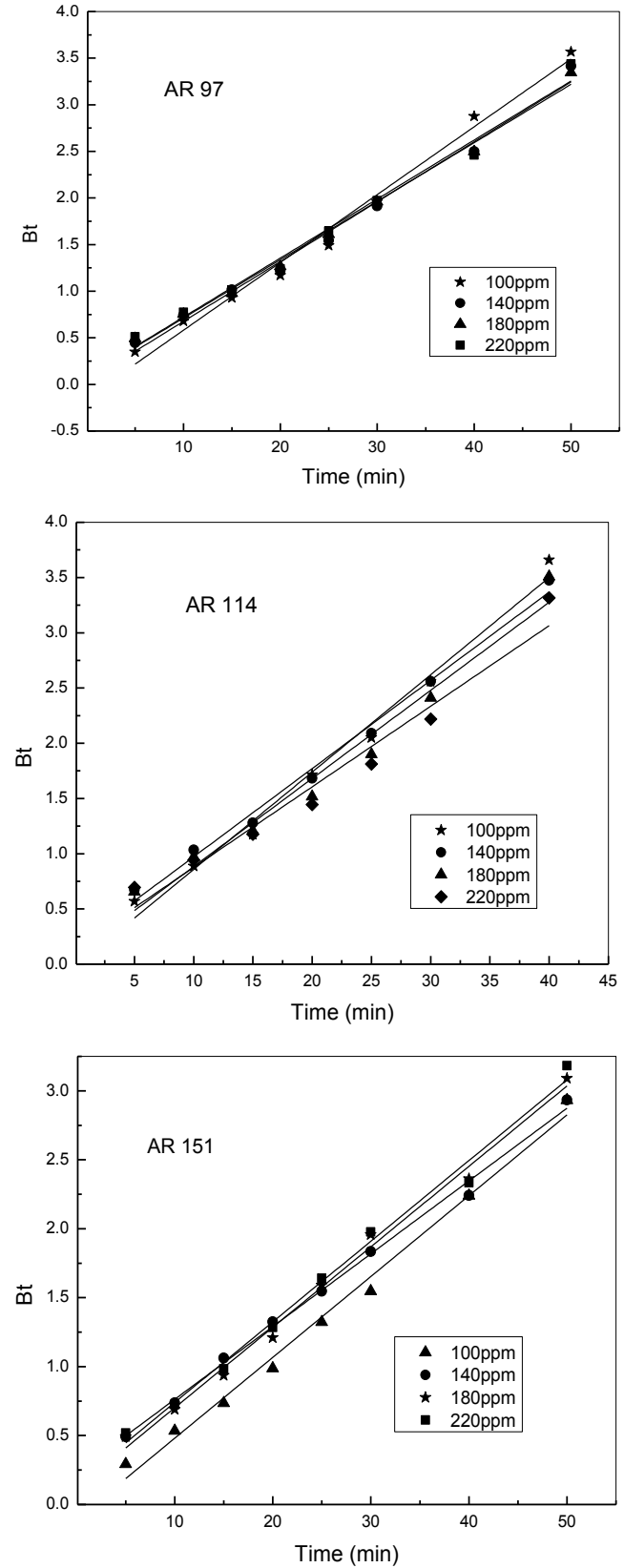

Figure 6. Boyd plot for the sorption of acid dyes onto Curcuma angustifolia scales.

and 2.59 for AR 151, which indicates favorable sorption. Temkin considered the sorbate-biosorbent interactions, and the heat of sorption for the molecules in the layer, reducing linearly with coverage (18). The sorption data were analyzed by means of the linear form of Temkin equation, and it was observed that this isotherm fitted well for all three acid dyes with $\mathrm{R}^{2}>0.99$. From Figure 4 , it was observed that a better fit for the experimental $q_{\text {e }}$ value is indicated by the Langmuir model for all three acid dyes, and proves the monolayer distribution of the dyes active site on the biosorbent surface, followed by Temkin and Freuendlich isotherm. The Freuendlich isotherm represents the poor fit for the experimental data, compared to the other isotherms. It is reasonably concluded that the sorption of acid dye is appreciably better in the biosorbent 
CS with sorption capacity in the order of AR $97>$ AR 114 $>$ AR 151 .

\section{Biosorption kinetics}

The kinetic study for the removal of AR 97, AR 114 and AR 151 onto CS is a time dependent sorption process, hence it is essential to know the sorption rate of acid dyes by CS in order to evaluate the efficiency of CS. The dye sorption process seems to proceed by a rapid binding of the sorbate onto the CS surface and reaches saturation in 75 minutes, for AR 97 and AR 151 and 60 minutes in AR 114.

The low correlation coefficient $\left(\mathrm{R}^{2}\right)$ values in CS for all acid dyes indicate that, pseudo first order is not applicable to the system. The kinetic data was tested for designing and modeling the sorption process, employing the pseudo first order model for dyes AR 97, AR 114 and AR 151, while the best fit was studied for the kinetic results with an initial dye concentration of $140 \mathrm{mg} / \mathrm{L}$ (Figure 5). The experimental $q_{e}$ value and the calculated $q_{e}$ values do not coincide for pseudo-first order model in all three acid dyes; and this confirms that the sorption of acid dyes onto the biosorbent does not provide the best fit for the Pseudo-first order model.

On plotting $\mathrm{t} / \mathrm{q}_{\mathrm{t}}$ vs. $t$, we can find $\mathrm{k}_{2}$ and hence the initial sorption rate $h$, can be determined utilizing the equation: $h=k_{2} q_{e}^{2}(4)$

Presently, the initial sorption rate $h$, rate constant $k_{2}$ and $\mathrm{q}_{\mathrm{e}(\mathrm{calc})}$ for AR 97, AR 114 and AR 151 can be obtained from the plot of $t / q_{t}$ vs. $t$. In CS, the correlation coefficient was $>0.99$ for pseudo-second order model in AR 97, AR 114 and AR 151 and therefore proves to be the well suited model for the sorption of acid dyes onto the biosorbent. The second order rate constant $\mathrm{k}_{2}$ was observed to decrease with increase in acid dye concentration onto the biosorbent. A similar trend was observed for decrease in $\mathrm{k}_{2}$ with increase in solute concentration (23). It was observed that the calculated $\mathrm{q}_{e}$ values agree well with the experimental $\mathrm{q}_{\mathrm{e}}$ values for the three acid dyes. This confirms that the sorption of acid dyes onto the absorbent, fitted well in the Pseudo second order model. This demonstrates that the biosorption of the acid dyes onto CS, follows the pseudo second order model and a chemisorption process follows in the present work.

The Elovich model assumes that the solid surface is energetically heterogeneous (24). The initial sorption rate $\alpha$ for the acid dyes increases from 40.94 to 127.79 for AR 97, 59.35 to 162.33 for AR 114 and 11.83 to 66.39 for AR 151 . This suggests that the sorption rate is good for all three dyes on the biosorbent. From Table 3, the extent of surface coverage $(\beta)$ decreases for all acid dyes with an increase in acid dye concentration, indicating that the availability of the biosorbent surface in CS decreases with an increase in AR 97, AR 114 and AR 151 dye concentration.

The intercept $C$ value for the acid dyes indicates the thickness of the boundary layer. The larger the intercept $\mathrm{C}$, the more the contribution of surface sorption at the rate controlling step (25). The increase in $\mathrm{C}$ with an increase in dye concentration for AR 97, AR 114 and AR 151 indicates the increase in the thickness of the boundary layer and internal mass transfer. The comparative fit for the sorption of AR 97, AR 114 and AR 151 onto the biosorbent, is shown in Figure 5. It was also observed from the results that the calculated $q_{e}$ value and the experimental $q_{e}$ values coincide with the intraparticle model for all three acid dyes.

Table 4 presents some of the low cost biosorbents employed for the sorption of acid dyes, alongside CS. In this study, it was observed that the sorption of the acid dyes by the biosorbent CS is good when compared with the low cost biosorbents reported in literature.

\section{Boyd model}

To predict if film diffusion or particle diffusion controls the rate of sorption onto the biosorbent, the Boyd kinetic model (18) was employed in the linear plots (Bt vs. time) of the three acid dyes. Hence, if the line passes through the origin, then particle diffusion is the slowest step, and if the linear plots were not passing through the origin in acid dye sorption onto CS, then film diffusion controls the sorption process. In this study, the Bt versus time plot (Figure 6) for AR 97, AR 114 and AR 151 at various concentrations were found to be linear, and does not pass through the origin. This confirms film diffusion in the sorption of AR 97, AR 114 and AR 151 onto CS.

\section{Conclusion}

The study revealed that CS scales can be utilized as an effective material in the sorption of acid dyes from aqueous solution. The sorption of acid dyes (AR 97, AR 114 and AR 151) onto CS was found to increase with the decrease in $\mathrm{pH}$, and increases with increase in biosorbent dosage. The isotherm data prove monolayer sorption for all acid dyes, and the adsorption capacity was found to be 350.87, 202.42 and $168.91 \mathrm{mg} / \mathrm{g}$ for AR 97, AR114 and AR 151 respectively. The kinetic study results prove that the pseudo-second order model fits well for all the acid dye sorption onto the biosorbent. Boyd plot results confirmed film diffusion process as the slowest step involved in all acid dye sorption process. Hence, it can be concluded that CS is an easily available low cost biosorbent having a good sorption capacity and can be utilized as an alternative material to costly adsorbents for the removal of dye in textile wastewater treatment process.

\section{Ethical issues}

The author declares that all the data collected during the present study are published in this work and there is no ethical issue in this work.

\section{Competing interests}

The Author declares that there is no competing interest in this biosorption work.

\section{Author's contribution}

The author declares that he performed all the experiments 
and drafted the manuscript.

\section{References}

1. Mittal A, Mittal J, Malviya A, Gupta VK. Adsorptive removal of hazardous anionic dye "Congo red" from wastewater using waste materials and recovery by desorption. J Colloid Interface Sci 2009; 340(1): 16-26. doi: 10.1016/j. jcis.2009.08.019.

2. Thinakaran N, Baskaralingam P, Pulikesi M, Panneerselvam P, Sivanesan S. Removal of Acid Violet 17 from aqueous solutions by adsorption onto activated carbon prepared from sunflower seed hull. J Hazard Mater 2008; 151(2-3): 316-22. doi: 10.1016/j.jhazmat.2007.05.076.

3. Gupta VK, Jain R, Nayak A, Agarwal S, Shrivastava, M. Removal of the hazardous dye-Tartrazine by photodegradation on titanium dioxide surface. Mater Sci Eng 2011; 31(5): 1062-7. doi: 10.1016/j.msec.2011.03.006.

4. Stephenson RJ, Sheldon JB. Coagulation and precipitation of mechanical pulping effluent_1. Removal of carbon, colour and turbidity. Water Res 1996; 30(4): 781-92. doi: 10.1016/0043-1354(95)00213-8.

5. Vlyssides AG, Loizidou M, Karlis PK, Zorpas AA, Papaioannou DJ. Electrochemical oxidation of a textile dye wastewater using a Pt/Ti electrode. Hazard Mater 1999; 70(1-2): 41-52. doi: 10.1016/S0304-3894(99)00130-2.

6. Gupta VK, Ali I, Saleh TA, Nayak A, Agarwal S. Chemical treatment technologies for waste-water recyclingan overview. RSC Adv 2012; 2: 6380-8. doi: 10.1039/ C2RA20340E.

7. Kim TH, Park C, Yang J, Kim S. Comparison of disperse and reactive dye removals by chemical coagulation and Fenton oxidation. J Hazard Mater 2004; 112(1-2): 95-103. doi: 10.1016/j.jhazmat.2004.04.008.

8. Yagub MT, Sen TK, Afroze S, Ang HM. Dye and its removal from aqueous solution by adsorption: a review. Adv Colloid Interface Sci 2014; 209: 172-84. doi: 10.1016/j. cis.2014.04.002.

9. Vasanth Kumar K, Porkodi K. Mass transfer, kinetics and equilibrium studies for the biosorption of methylene blue using Paspalum notatum. J Hazard Mater 2007; 146(1-2): 214-26. doi: 10.1016/j.jhazmat.2006.12.010.

10. Gupta VK, Suhas. Application of low-cost adsorbents for dye removal - A review. J Environ Manage 2009; 90(8): 2313-42. doi: 10.1016/j.jenvman.2008.11.017.

11. Bhatti HN, Nausheen S. Equilibrium and kinetic modeling for the removal of Turquoise Blue PG dye from aqueous solution by low cost agro-waste. Desalin Water Treat 2014; 55(7): 1934-44. doi: 10.1080/19443994.2014.927799

12. Khan TA, Sharma S, Khan EA, Mukhlif AA. Removal of congo red and basic violet 1 by chir pine (Pinus roxburghii) sawdust, a saw mill waste: batch and column studies. Toxicol Environ Chem 2014; 96(4): 555-68. doi: 10.1080/02772248.2014.959017.

13. Hameed BH, Krishni RR, Sata SA. A novel agricultural waste adsorbent for the removal of cationic dye from queous solution. J Hazard Mater 2009; 162(1): 305-11. doi: 10.1016/j.jhazmat.2008.05.036.

14. Khan TA, Rahman R, Ali I, Khan EA, Mukhlif AA. Removal of malachite green from aqueous solution using waste pea shells as low-cost adsorbent-adsorption isotherms and dynamics. Toxicol Environ Chem 2014; 96(4): 569-78. doi: 10.1080/02772248.2014.969268

15. Panda GC, Das SK, Guha AK. Jute stick powder as a potential biomass for the removal of congo red and rhodamine B from their aqueous solution. J Hazard Mater 2009; 164(1): 374-9. doi: 10.1016/j.jhazmat.2008.08.015.

16. Arami M., Limaee NY, Mahmoodi NM, Tabrizi NS. Equilibrium and kinetics studies for the adsorption of direct and acid dyes from aqueous solution by soymeal hull. J Hazard Mater 2006; 135(1-3): 171-9. doi: 10.1016/j. jhazmat.2005.11.044.

17. Ofomaja AE. Kinetic study and sorption mechanism of methylene blue and methyl violet onto mansonia (Mansonia altissima) wood sawdust. Chem Eng J 2008; 143(1-3): 8595. doi: 10.1016/j.cej.2007.12.019.

18. Vadivelan V, Vasanth Kumar K. Equilibrium, kinetics, mechanism, and process design for the sorption of methylene blue onto rice husk. J Colloid Interface Sci 2005; 286(1): 90-100. doi: 10.1016/j.jcis.2005.01.007.

19. Hameed BM, Daud FB. Adsorption studies of basic dye on activated carbon derived from agricultural waste: Hevea brasiliensis seed coat. Chem Eng J 2008; 139(1): 48-55. doi: 10.1016/j.cej.2007.07.089.

20. Langmuir I. The adsorption of gases on plane surfaces of glass, mica and platinum. J Am Chem Soc 1918; 40(9): 1361-403. doi: 10.1021/ja02242a004.

21. Malkoc E. Ni (II) removal from aqueous solutions using cone biomass of Thuja orientalis. J Hazard Mater 2006; 137(2): 899-908. doi: 10.1016/j.jhazmat.2006.03.004.

22. Treybal RE. Mass Transfer Operations. 3rd ed. New York: McGraw Hill, 1980.

23. Ho YS. Pseudo-isotherms using a second order kinetic expression constant. Adsorption 2004; 10(2): 151-8. doi: 10.1023/B:ADSO.0000039870.28835.09.

24. Pérez-Marín AB, Zapata VM, Ortuno JF, Aguilar M, Saez J, Llorens M. Removal of cadmium from aqueous solutions by adsorption onto orange waste. J Hazard Mater 2007; 139(1): 122-31. doi:10.1016/j.jhazmat.2006.06.008.

25. Hameed BH, Salman JM, Ahamed AL. Adsorption isotherm and kinetic modeling of 2,4-D pesticide on activated carbon derived from date stones. J Hazard Mater 2009; 163(1): 1216. doi: 10.1016/j.jhazmat.2008.06.069.

26. Chen B, Hui CW, Mckay G. Film-pore diffusion modeling and contact time optimization for the adsorption of dyestuffs on pith. Chem Eng J 2001; 84(2): 77-94. doi: 10.1016/S13858947(01)00193-0.

27. Sivaraj R, Namasivayam C, Kadirvelu K. Orange peel as an adsorbent in the removal of Acid violet 17 (acid dye) from aqueous solutions. Waste Manage 2001; 21(1): 105-10. doi: 10.1016/S0956-053X(00)00076-3.

28. Namasivayam C, Dinesh Kumar M, Selvi K, Ashruffunissa Begum R, Vanathi T Yamuna RT. 'Waste' coir pith-a potential biomass for the treatment of dyeing wastewaters. Biomass Bioenergy 2001; 21(6): 477-83. doi: 10.1016/ S0961-9534(01)00052-6.

29. Lee LY, Chin DZ, Lee XJ, Chemmangattuvalappil N, Gan S. Evaluation of Abelmoschus Esculentus (Lady's Finger) seed as a novel biosorbent for the removal of Acid blue 113 dye from aqueous solution. Process Saf Environ Protect 2014; 94: 329-38. doi: 10.1016/j.psep.2014.08.004.

30. Ferrero F. Dye removal by low cost adsorbents: Hazelnut shells in comparison with wood sawdust. J Hazard Mater. 2007; 142(1-2): 144-52. doi: 10.1016/j.jhazmat.2006.07.072.

31. Ho YS, Mckay G. Kinetic Models for the Sorption of Dye from Aqueous Solution by Wood. Process Saf Environ Prot 1998; 76(2): 183-91. 